\title{
Discussion: Innovative design for drainage structure on deep soft ground
}

Daiquan Yang PhD, CEng, NPER, RPEQ, MIES, MASCE, MISSMGE, MIEAust

Brisbane, QLD, Australia

Jay Ameratunga MEng, PhD, CEng, RPEQ, FIEAust

Senior Principal, Coffey Geotechnics Pty Ltd, Brisbane, Australia

Jacob Dunstan BEng, MEng, CEng, RPEQ, MIEAust

Principal, Coffey Geotechnics Pty Ltd, Brisbane, Australia
Ian Shipway BSC, RPEQ, MIEAust

Senior Principal, Coffey Geotechnics Pty Ltd, Brisbane, Australia

Alexander Litwinowicz FIE Aust

GHD Pty Ltd, Brisbane, Australia

\section{Contribution by A. Litwinowicz}

In the paper by Yang et al. (2015), the focus is on drainage structure A, but readers should be aware that there are other more significant structures of interest on the Northern Access Road Project (NARP), presumably also delivered under the overall design and construct (D\&C) contract. As a frequent user of the Northern Access Road, the discusser has observed at least two rounds of resurfacing at two other major bridge approaches due to significant settlements affecting riding quality and, presumably, user safety. In the discusser's experience, excessive post-construction settlement (PCS) can also put piled bridge foundations at potential risk due to the inevitable lateral foundation movements at abutments.

The discusser has over 30 years of experience in the design of road embankments in the Brisbane River floodplain that encompasses the project site, including monitoring the longterm settlement performance of several embankments. It was therefore a genuine surprise that the paper by Yang et al. (2015) promoted the innovation/success achieved when, close by within the same project and compressible regional marine clay formation, multiple pavement surface corrections have been deployed. A serious drawback with the paper is the absence of long-term monitoring, which restricts the topic to design/predictive aspects only. This discussion therefore explores both the interpretation of settlement data and comparison with actual performance.

The settlement performance at the key monitoring point S24 (control line MC10 CH11050) is worthy of closer scrutiny, noting that S23 and S25 share a similar form. Figure 9 from the original paper has been digitised and reproduced for S24 as Figure 10 and an Asaoka prediction (Asaoka, 1978) is shown in Figure 11 for the post-filling portion of the settlement record. The discusser has reviewed various soft soil projects for a variety of clients over a number of years and, invariably, the Asaoka method of settlement prediction has been a tool of choice for consultants (including some of the authors) in supporting their assessment of settlement progress.
The following observations are made.

- The settlement graph appears to plot total surface settlement without identifying the various contributors to the total settlement record.

- Similarly, the workings of the Caos software are not described but would appear to be focused on primary consolidation and, if this is the case, would omit other significant components of real embankment settlement during construction.

- The settlement rate at S24 at constant load post-completion of filling is significantly higher than the theoretically predicted Caos result from around day 250 onwards and, at $\sim 10 \%$ strain per log cycle, is indicative of ongoing primary consolidation, certainly not secondary consolidation.

- Consistent with this strain rate and in contrast to the Caos prediction, the Asaoka plot of actual settlement (Figure 11) shows a virtually parallel response to the 1:1 convergence line, indicating there was significant primary consolidation settlement yet to occur.

- There are no reported pore pressure data to track consolidation progress, the designer relying instead solely on the surface settlement response as discussed in Section 7.1 of the paper when referring to the revised parameters in Table 12. The absence of field pore pressure response to aid decision making is surprising and makes the selection of time of surcharge removal somewhat subjective and risky.

- Whilst the soft soil foundation sequence is complex, there are no extensometers to track where consolidation is occurring in the foundation, instead again relying on surface settlement alone to interpret the complexity of a deep soft soil profile.

- There are no long-term data on post-construction performance of the embankment foundations to proof the design, a characteristic the discusser has seen on a number of $\mathrm{D \& C}$ projects where long-term monitoring is unavailable and hence long-term performance is difficult to track and understand.

- Given the above, it appears that S24 may have been misinterpreted, in which case it would take a leap of faith to expect the real settlement response to suddenly slow 


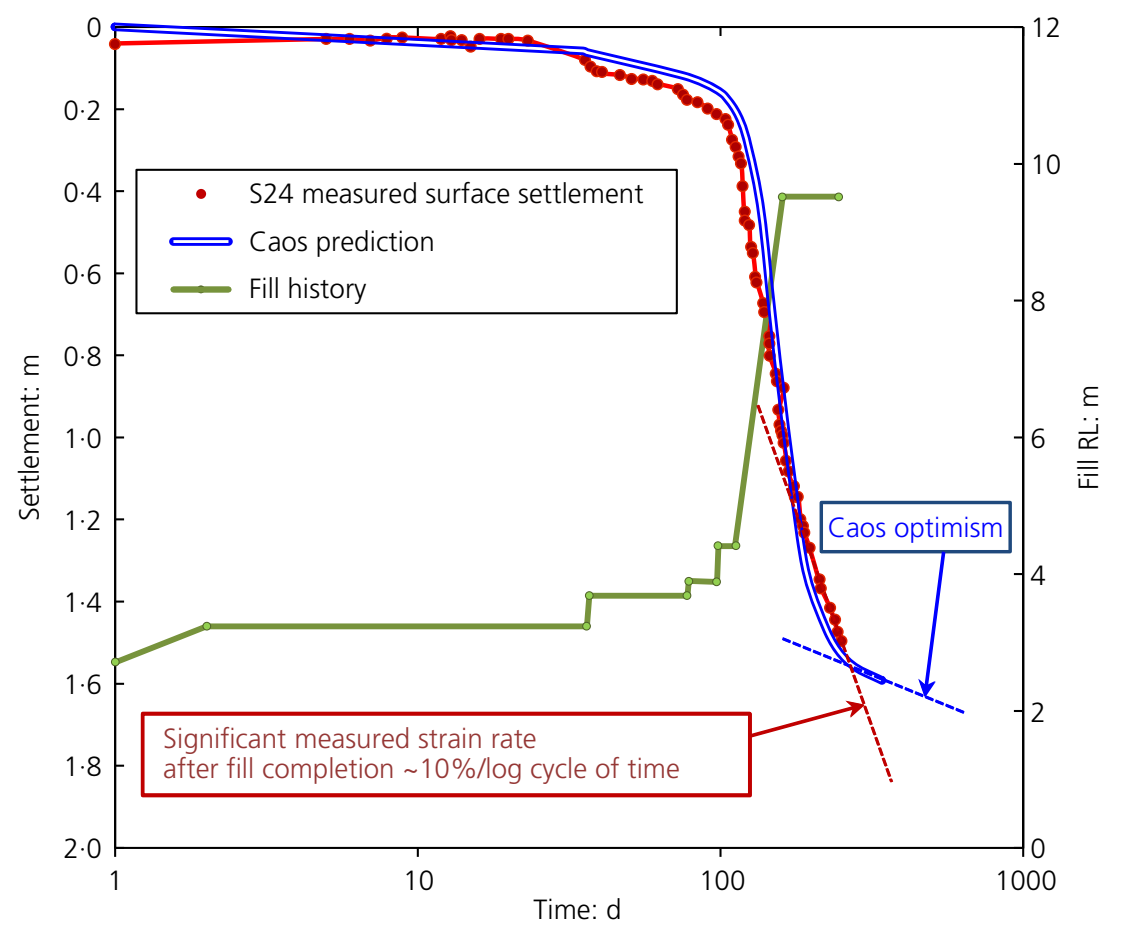

Figure 10. Plot of settlement against log time for monitoring point $\mathrm{S} 24$. $\mathrm{RL}$, reduced level

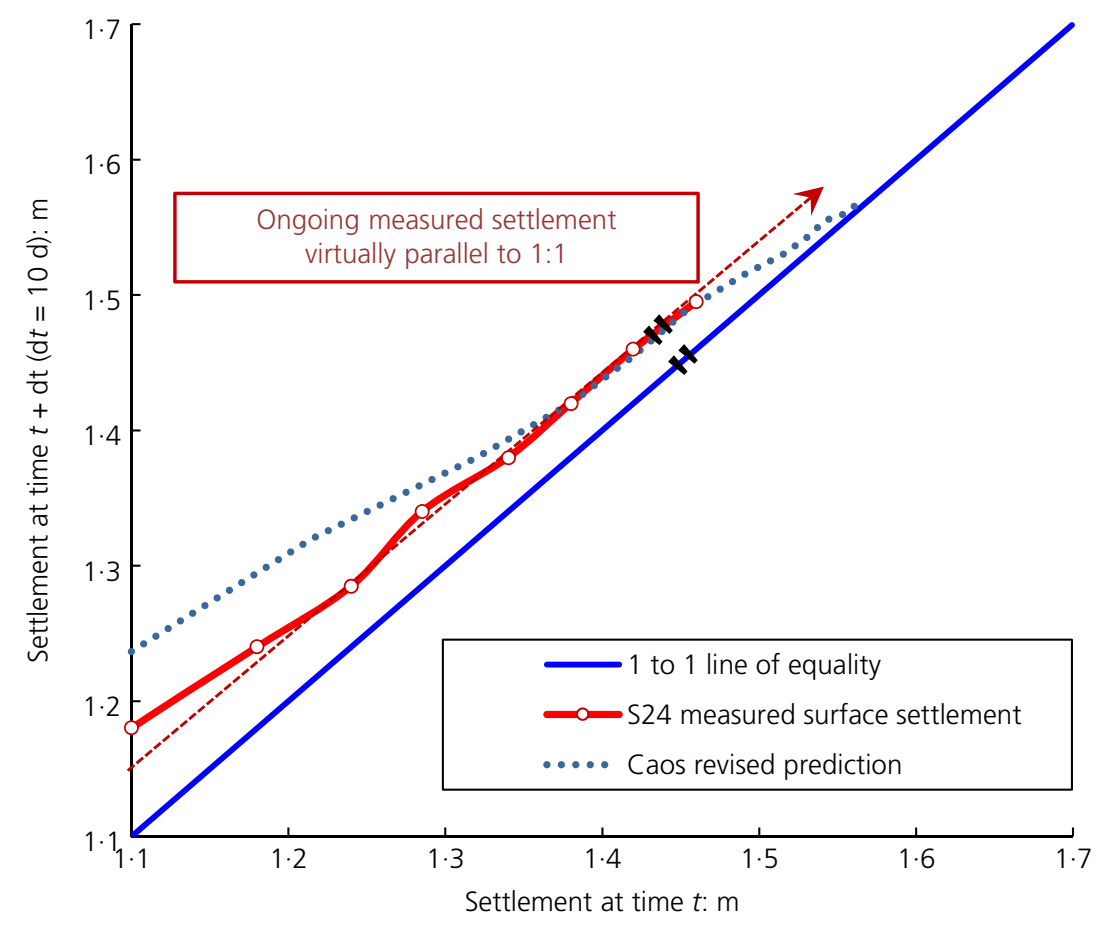

Figure 11. S24: Asaoka plot after fill completion

markedly and follow the Caos curve. In the Discusser's experience such optimism is not that unusual in the stressful, fast-track environment of a 'D\&C' contract.
The question then is whether the possibility of misinterpretation of the S24 settlement record is supported by actual settlement performance. It should be noted there are twin bridges at 


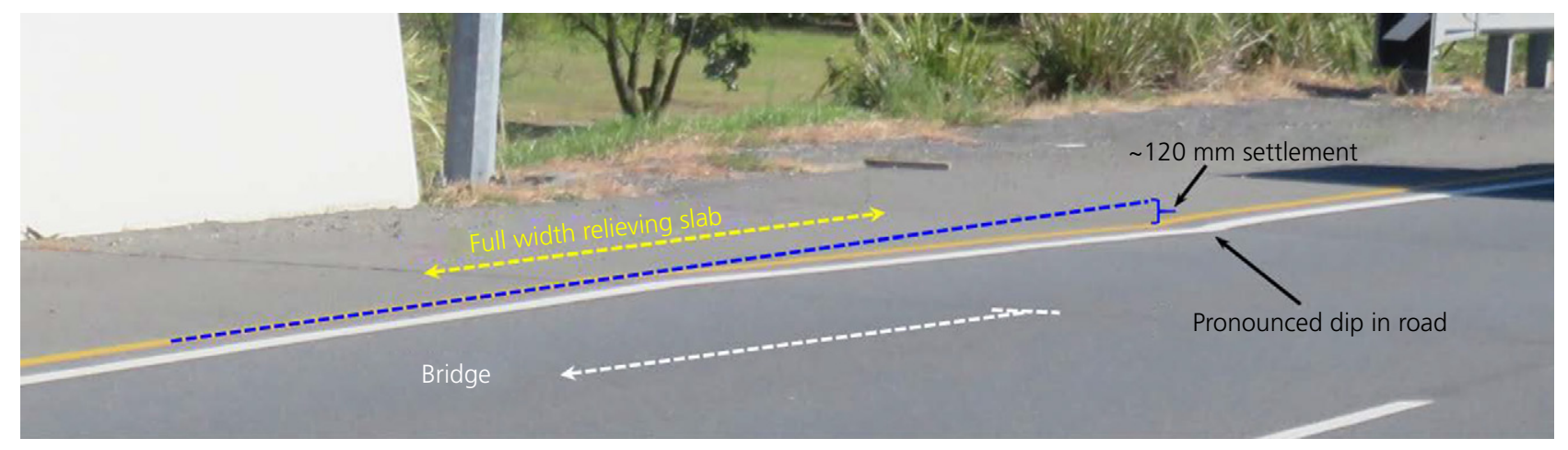

Figure 12. Western bridge northern abutment deck and relieving slab looking northwest, 17 October 2016

site A and all four abutments and road approaches now display similar performance and poor (bumpy) riding quality. Figure 12 is a recent photograph of the northern abutment of the western (inbound to the airport) bridge, which illustrates the settlement at the edge of the $8 \mathrm{~m}$ wide relieving slab compared with the bridge deck, which is fixed and sets the constant grade leading off the bridge. It is obvious that the approaches have settled substantially in the 7 years or so since road opening. Compared with the designer's adopted PCS criterion of $22 \mathrm{~mm}$ (maximum) in the following 40 years, a settlement of $\sim 120 \mathrm{~mm}$ since opening has been measured at this location.

The real settlement at this location is therefore nearly six times the PCS, and this has occurred in less than a fifth of the stipulated time. This therefore contradicts the claimed effectiveness of the wick drains and surcharge approach deployed at NARP as stated in the paper. It does, however, confirm that settlement monitoring was mismatched using the Caos software and the adopted analytical approach. The likely reasons for this would require a transparent understanding of the Caos architecture and proper foundation monitoring data, something that is absent in the paper. However, some likely pointers have recently been raised by the discusser on another soft soil project at Ballina, New South Wales (Litwinowicz (2016) discussing Kelly (2014)). The attention of readers is also respectfully drawn to the design $c_{\mathrm{v}}$ and $c_{\mathrm{h}}$ values adopted by the designer for loading into the normally consolidated range: these are more than an order of magnitude greater than longterm observations on other sites in the same marine clay formation treated with mandrel-driven wick drains (Litwinowicz and Hobbs, 1991) and the discusser's local knowledge of the properties of these compressible clays. Given the limited information presented in the paper, these and other aspects cannot be further explored here. Suffice to say that the settlement performance since pavement completion is proof in itself that the design parameters and analytical approach adopted failed by a wide margin to achieve the design intent for drainage structure $\mathrm{A}$ and its approaches.
Given the excessive PCS observed, and yet to occur, a further concern for drainage structure A is the effect of lateral loads on piles supporting the bridge in its current state, but even more so when the drainage canal is ultimately removed in front of the bridge abutments and the substantial existing lateral restraint is reduced.

From the above, it is unsurprising that the performance at other locations on the NARP has resulted in early surface correction, presumably because these locations have also used similar ground properties and foundation 'improvement' techniques.

In summary, the approach promoted in the paper has not delivered the intended performance at S24 and drainage structure A, and likely in a similar manner elsewhere on the NARP based on the corrector asphalt overlays observed since construction. The statement in the paper that

Overall, the performance of the preloaded embankment provided the confidence to the client, the designer and the contractor that wick drains would provide an effective improvement technique and that the adopted design parameters were reasonable for the local soils

may have seemed compelling based on the interpreted performance at the completion of construction, but unfortunately it was illusory as the actual post-construction performance tells a different story.

\section{Authors' reply}

The authors thank the discusser for the comments and the interest shown in the paper.

The main objective of the paper was to present the design aspects of the drainage structure, an innovative solution compared with routine design, particularly in relation to the alternative piling arrangement for managing excavation 
works underneath the drainage structure in the future. As the discusser correctly points out, the paper is limited to design/ predictive aspects only as there were no post-construction performance data to the authors' knowledge. The authors agree with the discusser that the absence of post-construction performance data is a characteristic seen on many D\&C projects.

The discusser comments on other projects in the same Brisbane River floodplain that encompasses the project site. There is thus no need to emphasise the characteristics of this floodplain and the presence of paleochannels within short distances, and therefore making comparisons between projects and/or locations is not always possible given that every case has its own unique complex conditions. Therefore, the discussion was limited to only the project site, as reported in the paper.

With hindsight, more information should have been provided on the software Caos (Consolidation analysis of soft soils), considering it was the tool used for the back-analysis. Caos is a program developed at the University of Sydney and has been in use for more than a decade. It has been successfully used on many projects across Australia and overseas. Importantly, it has been checked against other software such as Settle3D as well as one-dimensional analytical calculations. Caos is a Fortran program that carries out a finite-difference numerical solution of the one-dimensional equation of consolidation. It can analyse a multi-layered soil profile subjected to a series of loading sequences, which may include both constant and time-dependent loading. It also accounts for fill submergence, which was a very important problem to be solved at the project site. Soil creep is considered in the program via the conventional linear relationship between creep strain and the logarithm of time, with values input for the normally and over-consolidated states separately.

The discusser provides detailed comments on the Asaoka (1978) graphical construction and lists concerns over using the data for predictions included at the project site. However, as the paper states clearly, Caos was the predictive tool used for the predictions - the Asaoka method was not used. It is wellknown that the Asaoka method may not be accurate for profiles with more than one layer and for deep soft soils.
The Asaoka method with a first-order approximation is applicable to preloading cases with simple ground and loading conditions such as a single-layered stratum, single-staged loading and so on. For other preloading cases with a multilayered profile and multi-staged loading, curve fitting and matching methods using the finite-element method or the finite-difference method are recommended.

The discusser also comments on the non-tracking of consolidation using pore pressures. Although piezometers were installed at the site, the results were not used because their behaviour suggested malfunctioning. It is common practice in Brisbane and southeast Queensland, and for that matter in Australia, to use settlements for tracking consolidation rather than pore pressures. This is not unusual as several other projects in Brisbane have shown unreliability of pore pressure measurements, especially the delayed response. Hsi (2016), who has extensive experience in soft clay sites in the Brisbane floodplain, provides a detailed discussion of why settlement measurement is often used as the primary indicator when assessing the progress of consolidation.

\section{REFERENCES}

Asaoka A (1978) Observational procedure of settlement prediction. Soils and Foundations 18(4): 87-101.

Hsi J (2016) Soft soil engineering in practice. Proceedings of the 2016 Australian Geomechanics Society, Symposium - Ground Stabilisation Techniques for Problematic Soils and Unstable Rocks, Sydney, Australia, pp. 31-54.

Kelly RB (2014) Assessment of smear parameters for use in wick drain design. Proceedings of the Institution of Civil Engineers - Ground Improvement 167(13): 186-191, http://dx.doi.org/10.1680/ grim.13.00007.

Kelly RB and Litwinowicz A (2016) Discussion: Assessment of smear parameters for use in wick drain design. Proceedings of the Institution of Civil Engineers - Ground Improvement 169(2): 150-153, http://dx.doi.org/10.1680/jgrim.15.00034.

Litwinowicz A and Hobbs G (1991) The performance of a composite foundation on soft clay. Proceedings of Geo-Coast'91, Yokohama, Japan. Coastal Development Institute of Technology, Tokyo, Japan, vol. 3/12, pp. 347-352.

Yang D, Ameratunga J, Dunstan J and Shipway I (2015) Innovative design for drainage structure on deep soft ground. Proceedings of the Institution of Civil Engineers - Geotechnical Engineering 168(6): 483-497, http://dx.doi.org/10.1680/jgeen.14.00115 